\title{
Business approaches to quality improvement: why they are hard for the NHS to swallow
}

\author{
Christopher Pollitt
}

\section{Business approaches to quality improvement}

During the past two decades private sector business seems to have developed a series of powerful, generic approaches to improving the quality of its goods and services. Companies such as Rank Xerox, Ford Motor, Kodak, Taco Bell, Texas Instruments, Citibank, and Swedish Post have reported radical, quantum leaps in productivity and quality. During the past decade these approaches have been imported to the public sector on an increasingly large scale. The National Health Service (NHS) has certainly not been immune to this trend; indeed, it is awash with approaches to quality improvement which have their origins in private sector business practice. These include BS5750/ISO 9000 (see later), several varieties of total quality management, benchmarking and, most recently, business process re-engineering. Progress has been and undoubtedly is being made at many NHS sites and in many NHS contexts. Tangible quality improvements are being secured and often staff seem (in the jargon) to be "taking ownership."

Yet behind the facade of steady progress and the progressive adoption of modern techniques there are several unsolved and sometimes unacknowledged problems. In this paper I want to argue that where such contemporary approaches have been tried in the NHS their impacts often have been considerably less than those promoting them had predicted or hoped for. For example, a detailed study of attempts to implement total quality management at 38 NHS sites came to the conclusions that: "when measured against rigorously stated objectives, total quality management was not implemented successfully at more than two pilot sites in our sample."

Also, comparing NHS sites with two commercial controls: "The commercial companies made more progress than the NHS TQM [total quality management] sites on all TQM criteria except customer empowerment."1

If this is correct (and I suggest that it is not only correct but also applies to other business approaches as well as total quality management) then it raises an important question about why these allegedly powerful approaches seem to lose some of their steam in NHS environments. Is it because the approaches themselves are flawed and oversold, or because there are some factors which are special to the NHS, or some combination of the two?

Thus the main objective in the paper is to analyse the "fit" between approaches to quality improvement which have come from the private sector and the "host" conditions for these approaches within the NHS. Home grown or health specific approaches to quality improvement such as medical audit or the development of clinical protocols are therefore largely excluded from the discussion.

Analysis will suggest that certain prerequisites would need to be satisfied if total quality management, benchmarking, reengineering, and similar techniques were to have a more profound impact than in practice they have yet achieved. It should not be assumed, however, that the paper is arguing that these prerequisites necessarily should be met. Meeting them would be likely to generate other consequences, both positive and negative. It is doubtful whether the effort to apply business techniques full bloodedly - in the ways their originators or gurus recommend would prove worthwhile overall. Instead a more gradual mixed strategy is advocated.

The focus here will be on quality improvement efforts in acute hospital settings, although much of what follows probably applies in large measure to other healthcare contexts as well. However, the large modern hospital is a uniquely complex organisation, both in terms of the number of different products it delivers and because of the range of different occupational groups and technological systems which need to work smoothly together if overall quality is to be achieved. Thus there is a sense in which the hospital is one of the hardest tests any approach which claims to improve quality can face.

The nature of recent business approaches to service quality improvement

In the business world different approaches to quality have followed each other in rapid succession. In the following sections I will attempt to summarise the main characteristics of the best known techniques. The various approaches will be described and analysed in the same sequence as, chronologically, they achieved prominence in private sector management.

\section{British Standard 5750 ISO $9000^{2}$}

BS5750 is now something of a veteran in the quality improvement stables. In 1987 it acquired an international equivalent - ISO9000. BS 5750 had its origins in attempts to set standards for the supply of military equipment to the Ministry of Defence. The essential idea is that the processes by which goods or services are produced and delivered should be very clearly specified and documented and that 
everyone who needs to know should be familar with the relevant specification and documentation. An organisation which seeks registration for a particular process or system under BS5750/ISO 9000 pays a fee and subsequently, after a period of preparation, undergoes external assessment. If the assessor decides that the process concerned meets the requirements of the standard then the organisation can display its accreditation in its literature and on its products.

Although originally written with manufacturing industry in mind BS5750 was cast in such general terms that it proved possible to adapt and interpret it for application to almost any organisation that produces goods or services. However, in 1991 an additional part to the standard (ISO 9004-2) was introduced for services. Also, the ISO 9000 series of standards was adopted by the European Union as EN29000 and parts of BS5750 were revised and renumbered as BS EN ISO 9001: 1994.

The requirements for BS5750/ISO 9000 registration are complex, and lay heavy emphasis on documentation. The procedures for designing the product or service, controlling documents, purchasing key inputs, rendering the product identifiable and traceable, inspecting and taking corrective action all have to be set down in considerable detail. For example, in relation to document control the standard requires the organisation to be able to:

- Identify which documents need to be "control documents" (for example, manuals, handbooks)

- Only issue control documents which have been checked by designated staff

- Ensure availability of control documents to everyone who needs them

- Ensure removal or updating of out of date control documents

- Maintain a master list of those who are to receive control documents.

BS5750 does not itself set numerical quality standards. It does require a system for accurately identifying customer requirements, although it does not specify how this should be done. It has therefore been criticised for failing to accord a more salient role to user satisfaction. ${ }^{3}{ }^{4}$ It has also been said to be rather an expensive and essentially bureaucratic process which, of itself, does little to motivate or involve rank and file staff. ${ }^{5-7}$ Nevertheless, it does offer the customers of an organisation a guarantee that the organisation will have been through a strenuous process of focusing on the fine detail of its systems for assuring a consistent, well controlled product.

BS5750 has been adopted in several NHS settings. An early attempt to adapt the standard for NHS purposes was that of Rooney ${ }^{8}$ who proposed criteria in 20 distinct aspects of service provision. Some general practices and biomedical engineering departments are among the NHS units which have achieved accreditation. It has also been quite widely adopted by local government, especially in trading standards and highway departments. ${ }^{9}$

\section{Total quality management}

Total quality management is probably the best known contemporary approach to quality improvement. Conceptually it is far more ambitious than BS5750/ISO 9000. However, it is not easy to provide a definitive summary of total quality management because there are actually several major varieties, each with its own guru. ${ }^{10-12}$ Nevertheless, a recent survey of the (vast) literature suggested that total quality management usually includes at least the following elements:

- A corporate perspective, frequently entailing the production of an organisation-wide plan embodying specific quality goals

- The generation of real commitment and enthusiasm for quality all the way down the line from top management to the "shop floor"

- A transcendence of departmental and disciplinary boundaries (many quality problems typically arise within such boundaries)

- A willingness to make a substantial investment in training

- A commitment to continuous improvement: total quality management emphasises an ongoing process rather than a once and for all setting of quality standards

- An emphasis on avoiding mistakes or defects before they occur rather than correcting them retrospectively (and often expensively): this is encapsulated in the catch phrase "right first time."13

Thus total quality management covers a much broader front than BS5750/ISO9000, although there is no reason why a total quality management system should not incorporate the use of BS5750 as a way of guaranteeing the integrity of subsidiary processes within the larger whole.

The European quality award is explicitly founded on total quality management principles. From 1996 this award will invite public sector applicants. ${ }^{14}$ It is administered by the European Foundation for Quality Management which was set up by several large private sector corporations in 1988. Applications are built on the European Model for Business Excellence. This model accords specific point scores or weightings to different elements, as follows:

Management variables (total weighting, 50\%), leadership (10\%); people management (9\%); policy and strategy (8\%); resources (9\%); processes $(14 \%)$.

Results (total weighting, 50\%), people satisfaction $(9 \%)$ (in this case people means principally the organisation's workforce); customer satisfaction $(20 \%)$; impact on society $(6 \%)$; business results $(15 \%)$.

Total quality management has been quite widely adopted within the NHS - at least in name. In 198917 pilot projects were launched with the aid of pump priming finance from the Department of Health. In 1991 Hewlett Packard sponsored a new healthcare quality award for a "workgroup which is judged to have made the best use of these (quality) techniques - in particular the technique of total 
quality management." 15 The term total quality management was subsequently applied to many other quality improvement projects across many health authorities and trusts. The Department of Health financed an independent academic evaluation of the early projects, which identified key success factors and pointed to ways in which most of the NHS initiatives had fallen short of parallel efforts in the commercial sector. ${ }^{16}$ An introduction to one of the more successful NHS total quality management projects can be found in the NHS Management Executive's booklet Quality in action: the St Helier NHS Trust: a case study.'

A particularly interesting variant of total quality management is SERVQUAL, sometimes referred to as "gap analysis." Those who have developed the SERVQUAL approach claim to have identified five generic dimensions of service quality - tangibles (the physical appearance of facilities, staff, etc), reliability, responsiveness, competence, and empathy. An instrument is applied which measures, for each of the five dimensions, the gap between what the user of the service expects and what they perceive themselves as actually getting. This is known as the perception-expectation (or P-E) gap. Users are also invited to weight each dimension, by allocating 100 points across them. Pilot schemes with the SERVQUAL method have been carried out in outpatient clinics in Leicestershire, and the results compared with findings from the use of SERVQUAL in other sectors. ${ }^{10}$ Compared with the users of a sample of American banks, insurance companies, and a telephone company it would seem that Leicestershire outpatients have lower expectations of service but higher perceptions of the services that they actually receive.

\section{Benchmarking}

Benchmarking - another American import followed hard on the heels of total quality management. The idea behind it is deceptively simple. Find an organisation that is good (preferably the best) at some particular process that your organisation also performs (booking people into spaces; conducting pharmacological tests; managing large buildings), study carefully how it does it so well, make plans to raise your own performance to that level (or beyond), implement the plans, and monitor the results.

Benchmarking rapidly became famous when a best selling book was produced which explained how the technique had assisted the Xerox Corporation to regain the initiative upon discovering that their global dominance of the photocopying market had begun to disappear under challenge from competitors. ${ }^{20}$ British Telecom, Eastman Kodak, LL Bean, Trustee Savings Bank, and ICL were among the other household names which enthusiastically embraced the approach.

Most texts on benchmarking stress the importance of several features. Firstly, the process to be benchmarked should be one that is important to the users of the goods or services which the organisation concerned produces. Secondly, it is essential to achieve a deep understanding of the nature of the selected process as it currently operates within both the organisation wishing to improve its performance and the best practice organisation that is being used for comparison. Benchmarking therefore requires detailed research: it is not a "quick fix." -1 Thirdly, in a competitive environment there must be something of value in the benchmarking comparison for the best practice organisation as well as the aspirant. Attempts to benchmark a key function in a direct competitor may well encounter access problems. This is one reason why "functional benchmarking" is often recommended as a good way to begin. In functional benchmarking a comparator may be chosen who is unlikely to fear direct competition from the organisation wishing to benchmark - for example, a hospital concerned about outpatient bookings may seek to study the seat bookings process operated by a successful airline. Large organisations with many different delivery units may also conduct internal benchmarking to see why one particular unit seems capable of higher quality or higher productivity than most of the others.

In 1992 an NHS benchmarking reference centre was set up and various attempts were made to benchmark across the service. ${ }^{22}$ The application of benchmarking is by no means confined to business processes such as stockholding or record keeping. Clinical benchmarking has been used in obstetrics, paediatrics, and other specialties. Reported successes include reduced duration of stay, decreased requirements for blood transfusions, and improved pain management. ${ }^{23} 21$ In the autumn of 1995 the NHS Trust Federation and Newchurch and Company Ltd jointly launched a clinical benchmarking company that will offer NHS trusts comparative performance datasets..$^{25}$ There does not yet seem to have been any independent and systematic evaluation of NHS benchmarking activity. Unsurprisingly, however, the experience of early practitioners shows that success cannot be guaranteed. Typical problems include choosing an inappropriate process to benchmark (for example, an unimportant one); failing to implement change when monitoring data shows that improvement is possible; failures by senior management to invest sufficient time, resources, and support in the benchmarking process; attempts to benchmark too many measures or processes all at once, and inaccurate or meaningless data. ${ }^{20}$

\section{Business process re-engineering}

Business process re-engineering is also associated with a best selling book. American management consultants Michael Hammer and James Champy subtitled their text $A$ manifesto for a business revolution and they did not understate the power of their approach: "Reengineering, we are convinced, can't be carried out in small and cautious steps. It is an all-ornothing proposition that produces dramatically impressive results. Most companies have no choice but to muster the courage to do it."

Definitions of business process reengineering are quite elusive, or at least they 
are couched in such general terms that it can be hard to visualise. Johansson et al ${ }^{28}$ offer a typical example: "Business Process Reengineering is, by definition, the means by which an organisation can achieve radical change in performance as measured by cost, cycle time, service and quality, by the application of a variety of tools and techniques that focus on the business as a set of related customer-oriented core business processes rather than a set of organisational functions."

Like benchmarking, therefore, business process re-engineering entails a tight focus on the detail of key organisational processes. It tracks these across the vertical, functional divisions that characterise most large bureaucratic organisations (for example, in hospital terms, pathology, surgery, imaging, supplies, finance). In some respects it seems to be a kind of reborn operations research, although with a much more strategic and challenging manifesto than traditional operations research usually had. However, in most of its manifestations business process re-engineering seems to possess a more dramatic quality than benchmarking. In this respect it is perhaps closer to total quality management, in that it is often portrayed as not just a technique, more a philosophy.

Like total quality management, business process re-engineering has entered the NHS through pilot projects (at two teaching hospitals) supported by central NHS Executive finance. ${ }^{29}$ Also several other providers and purchasers have applied the fashionable label to current improvement projects. For example, Leicester Royal Infirmary has made a name for itself by creating a "one stop" neurology clinic where previously an outpatient might have had to make up to five visits. ${ }^{30}$ It is now going on to try to apply re-engineering principles to much more extensive tracts of the hospital's activities. ${ }^{31}$

It is too early for an extensive critical literature to have developed around applications of business process re-engineering in the NHS. In the business world, however, it has already attracted strong criticism as well as praise. In particular it seems (in its original, Hammer and Champy form) to say very little about the human relations part of change. ${ }^{32}$ This may not be unconnected with the fact that in its early commercial applications it was often associated with a radical decrease in the workforce. ${ }^{33}$ Various commentaries also expressed concerns about the way in which business process re-engineering can become a technocratic, top down exercise which focuses on organisational processes without sufficient assurance that changes in that area will affect those outcomes which matter most to the final customers.

To conclude this section it is worth noting that the more "apocalyptic" of the business approaches - total quality management and business process re-engineering - are high risk strategies, even in the private sector corporate environment from which they originate. They seem to have performed best when corporations face an immediate and visible crisis and are fighting to survive. ${ }^{34}{ }^{35}$ Even in these highly competitive circumstances disappointments and failures have not been at all rare. ${ }^{36}$ In a survey of 311 United States companies using total quality management $63 \%$ said that they had reduced product defects by less than $10 \% .{ }^{37}$ Certainly several knowledgeable commentators have raised doubts about the usefulness of total quality management in the public services sector. ${ }^{38}$ In fact the gurus of total quality management and business process reengineering are themselves candid about success rates: "As far as measuring the TQM [total quality management] results that have been achieved, there's a big information vacuum out there" 39 and "Our unscientific estimate is that as many as $50 \%$ to $70 \%$ of the organisations that undertake a re-engineering effort do not achieve the dramatic results intended." $" 40$

\section{Difficulties experienced by business approaches in NHS environments}

That business approaches pose challenges for the NHS is immediately apparent. In essence this is because they assume ways of running organisations which have not hitherto been the way in which most of the NHS - and certainly not the average large acute hospital - has been run. For example:

(a) Business approaches place considerable stress on the importance of following processes (chains of activity) right across the organisation, from beginning to end.

(b) They make no mention of professions or of any particular or distinctive authority that might be accorded to standards, rules, or guidelines emanating from professional bodies.

(c) They demand a holistic, corporate approach, driven by management.

(d) They also require the investment of considerable time and resource in specialised quality training.

(e) With the partial exception of BS5750/ IS0900 they emphasise the importance of shaping quality strategies around customer perceptions of quality.

(f) They claim both the possibility of and the need for radical rather than incremental change (especially business process re-engineering).

Such characteristics make business approaches something of a "foreign body" in most NHS acute units. Take the first element - the "whole process" approach. Typically, in large hospitals, complex, elongated, unstandardised processes involve many different departments and groupings at different stages. Patients with several problems may interact with dozens of different hospital staff (porters, nurses, paramedics, doctors, etc) as they complete an episode of treatment. Many delays and disjunctures can arise between different staff performing different activities (making an initial assessment; finding a bed; taking an $x$ ray film; getting results from pathology tests; scheduling theatre time; arranging discharge). In the past it would have been unusual for the whole of this long sequence to be managed as 
a single process, or for staff concerned with one activity to know much about the requirements of their colleagues in other parts of the hospital who were responsible for other activities. Yet this is the intended direction of business techniques such as total quality management and business process re-engineering.

Or again, the almost complete silence of business approaches with respect to the special status of professional knowledge (note $(b)$ ) may seem alien to the hospital setting. In the NHS professional groupings are both numerous and strong. Partly because of this managers often experience great difficulty in articulating or enforcing a "corporate approach" (note $(c)$ ). Resources and time (note $(d)$ ) are usually in very short supply.

What is more, business approaches enter an organisational landscape in which "standards" are already flowering in considerable profusion, although not quite in a manner of which advocates of total quality management and business process re-engineering would necessarily approve. The contemporary hospital is likely to be deeply entangled with medical audit, nursing audit, clinical audit, organisational audit and protocols, and procedural guidelines of various types. ${ }^{+1}$ However, it is unlikely that these will be well integrated, one with another, or that they will be firmly founded on market research into customers' wants, or that any one of these devices will cover the entire process that a patient goes through, from beginning to end.

In short, most hospitals exhibit a range of quality oriented activities, but of a type which fail to match many of the key elements identified at the beginning of this section (corporately conceived, customer driven, based on a holistic definition of key organisational processes). Unsurprisingly, existing quality improvement activities at NHS hospitals reflect the fragmented occupational structures and principal power relationships of those institutions.

Other features contribute to the difficulties experienced by "immigrant" business approaches. The NHS management, accounting, and control procedures may make it hard for a new quality improvement process to put down roots. Such initiatives can easily end up as "bolt on extras," run through special management structures which are only loosely related to normal operational management. Reliable baseline data about costs and processes - meat and drink to most business attempts to improve quality - can be very hard to come by within the NHS.

\section{Is there a way forward?}

If my analysis is broadly correct, is there a way forward? One easy, comfortable way is to dismiss business approaches out of hand. They can be stereotyped as "foreign" or "American." It can be pointed out that they sometimes fail even in the private sector. It can be claimed that the NHS is so special that it has little or nothing to learn from the world of profit oriented commercial companies. This general line of thought (not one that I invented) leads to the neglect or sabotage of business ap- proaches, and is used to justify the cynicism which NHS staff sometimes show when profit oriented ideals are introduced. This cynicism sits comfortably with the notion that, by and large, "the professionals know best" and should be left in peace progressively to raise their own standards through the reversed processes of improved training and peer review.

The argument advanced here, however, is that wholesale rejection of business approaches to service quality improvement is unwarranted and, indeed, an intellectually and even ethically untenable position to assume. The weaknesses of an exclusively profession based approach to quality improvement are clear to any student of NHS history. Medical audit, for example, remained an unusual and exceptional activity for almost 20 years after it became commonplace in the United States, and was eventually taken on board only when the government insisted on it in the 1989 white paper Working for patients. ${ }^{2}$ Even with earmarked financial support it then developed in such a way that most audit was non-comparative, weak on follow up, inaccessible to patients, and uncoordinated with other forms of quality assurance. ${ }^{+3}$

More broadly, until at least the mid-1980s the NHS could be said to be the paradigm case of professional paternalism, ${ }^{4+}$ a system in which the consumers of the service were only rarely permitted to advance their own preferences and concepts of quality. ${ }^{+\bar{T}}$ The tide of cultural deference that permitted this stage of affairs to continue is running out fast. What is more the advent of the NHS internal market created purchasing authorities which, as they mature, are less likely to be willing to accept as sufficient the fragmented and purely professional approaches to quality improvement. In a market or quasimarket relation independently accredited, patient oriented approaches to quality assurance may well be the kinds of tokens of good faith that purchasers come to demand from providers. ${ }^{\text {to }}$

There remains, therefore, the search for some sort of middle way. The aim would be to combine the strengths of professionalism with the insights and dynamism of commercial consumerism, while discarding the characteristic weaknesses of both. In my view such an approach would be unlikely to come in the form of a particular package of specific, universally applicable activities or techniques, complete with logo or acronym. More probably it would consist of a set of design criteria which any local quality improvement scheme would be expected to meet (if a logo is necessary one can be inverted locally). The criteria would embody some of the key insights (and vast experience) gained in the commercial sector, but the substantive arrangements for meeting these criteria would be a matter for the particular trust (in partnership with other stakeholders such as purchasers and Community Health Councils to decide.

Each researcher would no doubt produce a slightly different list of design criteria, or at least different emphases within the list. However, certain themes recur so often that they would seem to be universally supported, 
at least among those academics who have attempted to interpret business approaches for public service contexts. In the following paragraphs these themes are briefly enumerated.

(1)The main focus for quality improvement efforts should be the whole process as experienced by the patient, not just fragmented pieces of that process. In an NHS context this makes notions such as "integrated care pathways" a promising place to start, always provided that the patients themselves are given an active and continuing voice in service redesign ${ }^{47}$ and that the pathways do not stop at the door of the ward, or even the hospital. Monoprofessional audits and other forms of peer review can significantly contribute to improvement of such broad pathways or processes, but only if they are selected and planned to fit in with the bigger picture.

(2) Inside the organisation, there needs to be both a team or multidisciplinary forum at the working level and explicit and well informed leadership from the top. Processes cross the frontiers between different departments and wards and the staff in each unit need a better understanding of each other's problems. ${ }^{48}$ For hospitals the level of involvement of consultants is almost always a crucial factor. Looking back, the leader of one of the NHS's most successful total quality management schemes said that if he were starting again he would go for much more medical involvement in the design. ${ }^{49}$ This sentiment is echoed at many other hospitals. It may be that it is more important to persuade consultants to spend their valuable time in multidisciplinary teams than in monoprofessional audits.

(3) For the team approach to succeed at working level real decentralisation of both authority and budgets is usually required. ${ }^{50}$ There may also be a case for re-examining incentives (not merely salaries) so as to be able to recognise quality improvements.

(4) Quality should be everyone's responsibility rather than something which is hived off to a separate unit or directorate. ${ }^{51}$ The approach that was common in the NHS in the mid1980s - appointing a nurse as "director of quality" but leaving all else unchanged - is unlikely to make any fundamental impact.

(5) Intensive training is likely to be needed. It should mirror the multidisciplinary team approach advocated above. The team that trains together works together.

(6) The trade off between quality and cost should not be avoided but rather confronted at an early stage. Many quality improvements may be available at low or no cost, but this should be shown by careful analysis, not assumed. One useful way of beginning this can be to attempt to estimate the cost of existing quality failures. ${ }^{52}$ If medical and clinical audit processes could be linked to cost data (more often and more closely than they have usually been in the recent past) that would itself be a considerable step forward.

(7) Top management needs to be firm and clear with the message that quality improve- ment is likely to involve changes in job content (not just doing the same things faster or more accurately). Some of these changes may trespass across what had hitherto been seen as occupational or departmental demarcation lines. This needs to be on the agenda from the start (it will be in staff's minds anyway). It may be possible to reduce anxiety by coupling it with some form of employment guarantee, or by strong commitments to retraining and job enrichment through more generic forms of working. Ultimately the boundaries of medical practice itself will have to come under scrutiny (for example, through consideration of the wider use of nurses - see Richardson and Maynard ${ }^{53}$ ). There is no logical reason why doctors should be the only occupational group whose contribution to processes and care paths remain immune to reanalysis.

(8) Another sensitive issue for urgent discussion is measurement. Attempts at quality improvement benefit enormously from comparisons with measured baselines (benchmarks) and from continuous monitoring to assess the extent to which planned improvements have actually been achieved. Going "softly softly" on the measurement issue is seldom appropriate. ${ }^{54}$

(9) Most fundamental of all, most contemporary business approaches stress the indispensability of research into customer wants and expectations. There is little point in just measuring achieved patient satisfaction unless there is also systematic enquiry into why patients want what they want, and what factors most influence their expectations (see Edvardsson et $a l^{55}$ ). The message from the business world is that such research will probably yield some surprises for even the most experienced provider of services.

Time after time, analyses of business organisations have shown that there is a need for better understanding of what the customer wants and expects. This research also indicates that most quality failures are due to faulty, complicated, or inappropriate systems rather than to individual people simply making mistakes. What is more, most of these failures can be traced to problems which occur across internal organisational boundaries between different departments or occupational groups. There is every indication that these broad findings hold true for hospitals too. Yet until recently a high proportion of NHS training has been devoted to improving the professional skills of the individual person. There is much for healthcare staff of all kinds to learn from the business literature, but no need to swallow it wholesale.

Part of the work on which this paper is based was financed by a grant from the British Council and the Flemish Research Council. Intellectually I am in particular debt to Professor Geert Bouckaert of the Catholic University of Leuven and to my Brunel colleagues Richard Joss, Justin Keen, and Tim Packwood. The responsibility for the views expressed is mine alone.

1 Centre for the Evaluation of Public Policy and Practice. Total quality management in the National Health Service: final report of an evaluation. Uxbridge: CEPPP/Brunel University, 1994:3-4.

2 British Standards Institute. Quality Systems Standard. London; BSI, 1987. 
3 Dale B, Oakland J. Quality improvement through standards. Cheltenham: Stanley Thornes, 1991

4 Centre for the Evaluation of Public Policy and Practice. Total quality management in the National Health Service: final report of an evaluation. Uxbridge: CEPPP/Brunel final report of an evaliut
University, 1994:3.27.

5 Freeman-Bell G, Grover R. The use of quality management in local authorities. Local Government Studies 1994;20:4.

6 Gaster L. Quality in public services. Buckingham: Open Univers

7 Ovretveit J. Auditing health service quality. Paper presented to the annual conference of the European Healthcare Management Association. Karlstad, Sweden: EHMA, 1992:121

8 Rooney E. A proposed quality system specification for the National Health Service. Quality Assurance 1988;14: $45-53$.

9 Freeman-Bell G, Grover R. The use of quality management in local authorities. Local Gocinnemt Studies 1994:20: 55469.

10) Loffler E. The modemization of the public sector in an international comparatize perspective: concepts and methods of aziarding and assessing quality in the public sector in (OECI) countries. Speyer: Speyer Forschungsberichte 1995:151

11 Gaster L. Quality in public sereices. Buckingham: Open Lniversity Press, 1995:75-7.

12 Whittle S. Total quality management: redundant approaches to culture change. Otrality of working: nows and abstracts 1992;110:8-13.

13 Centre for the Evaluation of Public Policy and Practice. Total quality management in the National Health Sorrice: final report of an ecaluation. Uxbridge: CEPPP/Brunel final report of an
Unicersity, $1994: 1$.

14 Loffler E. The modernization of the public secter in an international comparative perspective: concepts and methods of awarding and assessing quality in the public sector in OECD countries. Spever: Spever Forschungsberichte 1995:4.45.

15 The healthcare quality award [leaflet]. Hewlett Packard, 1991

16 Centre for the evaluation of public policy and practice. Total quality management in the National Health Service: final report of an eraltation. Lxbridge: CEPPP/Brunel
University, 1994 .

17 NHS Management Executive. Quality in action: the St Helier NHS Trust: a case stud?. Leeds: NHSME, 1993.

18 Zeithmal V, Parasuraman A, Berry L. Delicering serrici quality. New York: Free Press, 1990.

19 Hart M. Measuring perceptions of quality in NHS clinics using the SERVQLAL methodology. In: Richards B, ed. Current perspectices in healthare computing. Weybridge: BJHC, 1996.

20 Camp R. Benchmarking: the search for industry best practicis that liad to a superior performance. Milwaukee: Quality Press, 1989

21 Bendell T, Kelly J, Merry T. Quality: measuring and monitoring. London: Century Business, 1993

22 Bullivant J, Naylor M. Best of the best. Health Siricic Fournal 1992; (27 August):24-5.

23 Leicestershire Roval Infirmary NHS Trust. Quality standards in medicine. IFM Update 1995;17:4-5.

24 North West Paediatric Benchmarking Group. Paediatric benchmarking: a success story. VFM Update 1995; $17 \cdot 6 \cdot 7$

25 The Clinical Benchmarking Company Limited. Creating comparisons and setting standards. IFiM Lpdati 1995; 17:8-9.

26 Trouble-shooting benchmarking activity. IFM Updati 1995;17:20.

27 Hammer M, Champy J. Re-engincering the corporation: a manifesto for business revolution. London: Nicholas Brearley, 1995:5.
28 Johansson $\mathrm{H}, \mathrm{McHugh} \mathrm{P}$, Pendlebury A, Wheeler $111 \mathrm{~W}$ Business process re-engineering: breakpoint stratcgies for market dominance. New York: Wilev, 1993:15 6.

29 Millar B. Time machine. Health Service foumal 1995:11

30 Millac P, Liddle B, Reid S. The single visit neurology clinic foumal of the Association for Quality in Healthiar $1994 ; 22:+3-50$

31 Leicestershire General Hospital NHS Trust. Putting theory into practice. IFM 1995;17:23-5.

2 Willmott $\mathrm{H}$. Business process re-engineering and human resource management. Persomel Revicii 1994;23:34-46.

33 Conti R, Warner $M$. Taylorism, teams and technology in "re-engineering" work-organization. Niw Tichnology: IF"ork and I:mploymont 1994:9:93-102

34 Howe R, Gaeddert D, Howe M. Quality on trial. London: McGraw-Hill, 1992:4.

35 Hammer M, Champy J. Re-ingineering the corporation: a manifesto for busimess rezolution. London: Nicholas Brearley, 1995.6.

36 Hall $G$, Rosenthal J, Wade J. How to make re-engineering really work. Harcard Business Review 1993:119.31.

37 Howe R, Gaeddert D, Howe M. Quality on trial. London: McGraw-Hill, 1992:5.

38 Wilson L, Durant R. Evaluating TQM: the case for a theory driven approach. Public Administration Revicie 1994: $54: 137-45$

39 Juran J. Spech to thi (iencral Aicounting ()ffice. Washington: 1991:200.

40 Hammer .M. Champy J. Re-congincering the corporation a manifeste for busines reolution. Iondon: Nicholas

41 Pollitt $C$. The struggle for quality: the case of the National Health Service. Policy and Politics 1993;21:161 70.

12 Pollitt $C$. The politics of medical quality: auditing doctors in the LK and the LSA. Health Sirices Management Research 1993;6:4-34

43 Kerrison S. Packwood T, Buxton M. Monitoring medical audit. In: Robinson R, Le Grand J, eds. Eicaluating thic NHS reforms. London: King's Fund Institute, 1994 $155-77$.

44 Klein R. Thi politics of the NHS. London: Longman, 1983.

45 Williamson C. Whose standards? Consumer and professional standards in health care. Buckingham: Open University Press, 1992.

46 Walsh K. Public sericiss and market mechanisms: competition, contracting and the new public management. Basingstoke Macmillan, 1995:36-8

47 Edvardsson B, Thomasson B, Ovretveit J. Quality of servicu. making it really acork. London: McGraw-Hill, 1994 $214-20$.

48 NHS Management Executive. Quality in action: the St Helit' NHS Trust: a case' studv. Leeds: NHSME, 1993.

49 Interview with Quality Development Manager St Helie NHS Trust, 15 December 1994

50 Gaster L. Quality in public sirvices. Buckingham: Open University Press, 1995:84

51 NHS Management Fxecutive. Ouality in ation. the St Hidic. NHS Trust: a case studs: Leeds: NHSME, 1993.

52 Joss R. Costing non-conformance at an NHS hospital: pilot study. In: Pollitt C, Bouckaert G, eds. Quality improcement in Europian public sericics. London: Sage, 1995:10310.

53 Richardson G, Maynard A. Fewer doctors? Mon nurses? A revilew of the knowidedge base of doctor-murse substitution. York: Centre for Health Economics, 1995. (Discussion Paper 135.)

54 Pollitt C, Bouckaert G, eds. Improving the qualit of Europian public serrices. London: Sage, 1995.

55 Edvardsson B. Thomasson B, Ovretveit J. Quality of servic. making it really awk. London: McGraw-Hill, 1994 10010 